\title{
DEMENCIJA NAKON MOŽDANOG UDARA
}

\author{
Osman Sinanović \\ Medicinski fakultet Univerziteta u Tuzli, 75000 Tuzla; Sarajevo Medical School, University Sarajevo \\ School of Science and Technology, 71210 Ilidža, Sarajevo
}

Autor za korespondenciju:

Osman Sinanović

osman.sinanovic1@gmail.com

primljen: 2019, prihvaćen: 2019, objavljen: 2020.

\section{Apstrakt}

Moždani udar (MU) ili cerebrovaskularni inzult (CVI), koji se može definirati kao disfunkcija mozga koja nastaje zbog poremećaja protoka krvi kroz mozak, predstavlja drugi najčešći uzrok smrti odraslih u svjetskoj populaciji (1). MU pogađa 33 miliona ljudi svake godine u svijetu, a jedna trećina MU dešava se u zemljama u razvoju. Demencija nakon moždanog udara (post-stroke dementia / PSD) ili kognitivno oštećenje nakon moždanog udara (poststroke cognitive impairment / PSCI) pogađa oko jednu trećinu preživjelih. Opisane su različite definicije i sinonimi za PSD i PSCI. S obzirom na to da je PSD najsveobuhvatnija, predloženo je da se ovaj termin koristi za sva kognitivna oštećenja koja se razvijaju nakon moždanog udara, neposredno ili nešto kasnije. Prevalenca PSD se kreće od 20 do 80\%, što varira među zemljama iz kojih stižu saopštenja, ovisno o rasi i dijagnostičkim kriterijima. Rizik za razvoj PSD vezan je kako za različite demografske faktore kao što je dob, nivo obrazovanosti, zanimanje, tako i za različite vaskularne faktore (1, 3-4). Vaskularni faktori rizika kao što su hipertenzija, diabetes mellitus, hiperlipidemija, pušenje, atrijalna fibrilacija, povećavaju rizik za razvoj kako samog MU tako i PSD. Nadalje, ponavljanje moždanih udara povećava rizik za razvoj PSD, od oko 10\% nakon prvog MU do 30\% nakon ponavljajućeg. Prevencija PSD može se postići prije svega prevencijom MU. Na drugoj strani primjenjuju se različite strategije u cilju ublažavanja kliničkog toka PSD, kao što je smanjenje krvnog pritiska, primjena statina, neuroprotektivnih i antiinflamatornih lijekova, bez uvjerljivih dokaza njihove efikasnosti. Analiziraju se i mogući pozitivni učinci intervencija u sferi životnih stilova, učinci različite fizičke aktivnosti, kognitivnog treninga i dr. Za sada ne postoji uvjerljiv efikasni tretman PSD, ali lijekovi koji se primjenjuju u tretmanu Alzheimerove demencije (holinesterazni inhibitori, memantin) ipak pokazuju određenu efikasnost. Nadalje, u toku su različite kliničke studije koje su obećavajuće $(1,3)$.

Ključne riječi: demencija nakon moždanog udara, učestalost, faktori rizika, prevencija, tretman. 


\section{Uvod}

Moždani udar (MU) ili cerebrovaskularni inzult (CVI), koji se može definirati kao disfunkcija mozga koja nastaje zbog poremećaja protoka krvi kroz mozak, predstavlja drugi najčešći uzrok smrti odraslih u svjetskoj populaciji (1). Svake dvije sekunde neko u svijetu doživi moždani udar, a svakih šest sekundi neko od njega umre. MU pogađa 33 miliona ljudi svake godine u svijetu, a jedna trećina MU se dešava u zemljama u razvoju (2). Međunarodne epidemiološke studije pokazuju da stopa raste eksponencijalno s godinama, od 0,3\%o u trećoj dekadi života, do 30\%o u osamdesetim i devedesetim godinama života, što predstavlja prosjek od 1-2\%o. I pored značajnog napretka u primarnoj prevenciji, dijagnozi i terapiji, MU se, kao uzrok smrti, nalazi i dalje na drugom/trećem mjestu iza kardiovaskularnih i malignih oboljenja, a vodeći je uzrok onesposobljenosti u većini zemalja svijeta. U zemljama u tranziciji, kao što je Bosna i Hercegovina, MU se nalazi na vrhu ljestvice mortaliteta zajedno s oboljenjima srca.

Prema Evropskom udruženju za MU, broj osoba koje dožive moždani udar porast će za čak 34 posto u idućih 15 do 20 godina. Doći će i do 25-postotnog porasta broja ljudi koji žive s posljedicama moždanog udara kao hroničnim stanjem i predviđanja govore da će ih u Evropi biti 4,6 miliona, što će zahtijevati mnogo više od sadašnjih 45 milijardi eura, koliko se troši na liječenje posljedica moždanog udara. MU je vodeći uzrok mortaliteta u SAD i odgovoran je za smrt preko 140.000 smrti Amerikanaca godišnje, što čini 1 od 20 smrti općenito. MU je i vodeći uzrok onesposobljenosti u SAD. Tako npr. u 2011, oko 19\% bolesnika je nakon tretmana u nekom neurološkom odjelu bilo transferirano u neki rehabilitacioni centar, $25 \%$ ih je bilo upućeno u neki od sestrinskih odjela za njegu, a 12\% ih je bilo upućeno na kućnu njegu uz pomoć patronažnih servisa (3-5).

Incidenca MU varira od regije do regije i iznosi od 100 do 400 novih slučajeva na 100.000 stanovnika godišnje. Incidenca MU je veća kod muškaraca, raste s godinama starosti i udvostručava se na svakih deset godina poslije 55 godine starosti. Prevalenca MU se kreće od 500 do 900/100.000 u nerazvijenim zemljama. Podaci za Francusku govore o godišnjoj incidenci od 114/100.000 osoba opće populacije, u Njemačkoj je to 350/100.000, u Italiji 223/100.000, Španiji 141-223/100.000, Engleskoj 161/100.000, Hrvatskoj 251/100.000. Procjene za BiH slične su kao u Hrvatskoj. Stopa prevalence se kreće između 5\% i nekoliko procenata, ovisno o stepenu razvijenosti regije/ zemlje (6). Najveće epidemiološke razlike su u mortalitetu. MU čini 10-15\% 
svih letalnih ishoda, a preko $80 \%$ kod ljudi starijih od 65 godina. Zabilježeni mortalitet MU u razvijenim zemljama je između 30 i 100/100.000 za oba spola, dok je u nerazvijenim zemljama višestruko veći, 200-250/100.000.

Osim što se radi o bolesti s veoma visokim stepenom mortaliteta, podjednako je ozbiljna i činjenica da je ovo neurološka bolest s najvećim stepenom invaliditeta. Računa se da jedna trećina bolesnika umre unutar prve godine nakon MU, jedna trećina ima vrlo dobar funkcionalni oporavak, ali jedna trećina bolesnika nije sposobna za samostalno funkcionisanje i život bez pomoći drugog lica. Ovo oboljenje dramatično remeti život u porodici i okruženju bolesnika i stoga predstavlja ne samo medicinski nego i značajan socijalni i ekonomski problem društva u cjelini. MU podrazumijeva tri kategorije: tranzitorna ishemijska ataka (TIA), ishemijski moždani udar (IMU) i hemoragijski moždani udar (HMU). Ove tri kategorije nadalje uključuju embolijski i trombički udar, intracerebralnu i subarahnoidalnu hemoragiju.

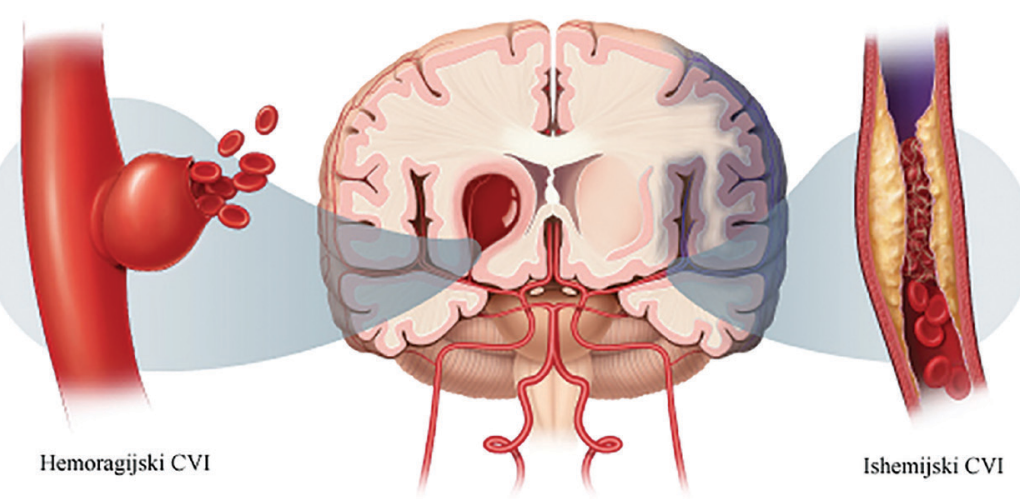

Slika 1. Osnovi tipovi moždanog udara

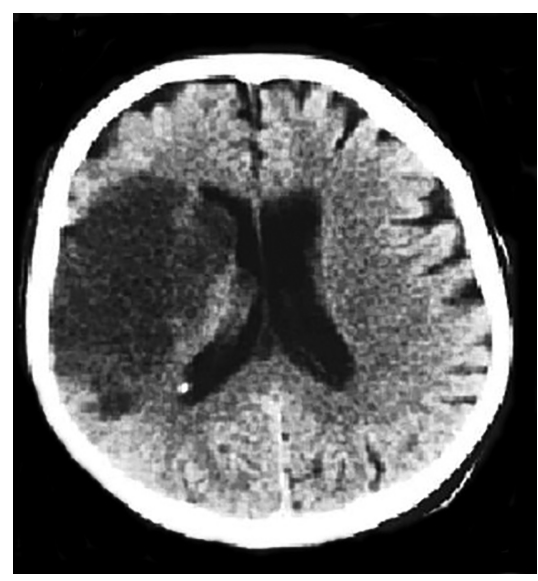

Slika 2. Kompjuterizovana tomografija kod ishemijskog moždanog udara u području srednje moždane arterije desno 
Postoji u biti više načina klasifikacije MU: klasifikacija prema Međunarodnoj klasifikaciji bolesti (MKB), kliničko-patološka, etiološka, topografska itd. Međutim, u svakodnevnoj kliničkoj praksi najviše se koristi klasifikacija prema vrsti patološkog procesa. Prema ovoj podjeli MU se dijele u dvije velike grupe: IMU (Sl. 1 i 2), koji se razvija zbog nemogućnosti snabdijevanja moždanog tkiva kiseonikom i glukozom uslijed okluzije (začepljenja) krvnog suda i čini $75-80 \%$ svih MU te HMU koji može biti po tipu intracerebralne (ICH) (S1. 3) ili subarahnoidalne hemoragije (SAH) (Sl. 4). Ako dođe do "izliva" krvi unutar moždane mase, nastaje ICH, koja čini 15-20\% MU, dok prodor krvi u subarahnoidalni prostor dovodi do SAH, koja čini 5-10\% svih MU (7-8).

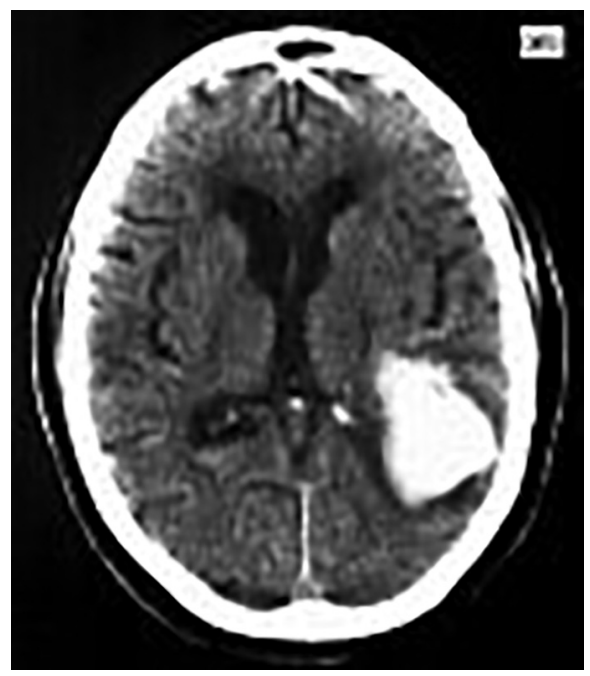

Slika 3. Kompjuterizirana tomografija mozga na kojemu se vidi lijevo temporoparietalno hiperdenzna area koja odgovara intracerebralnom hematomu

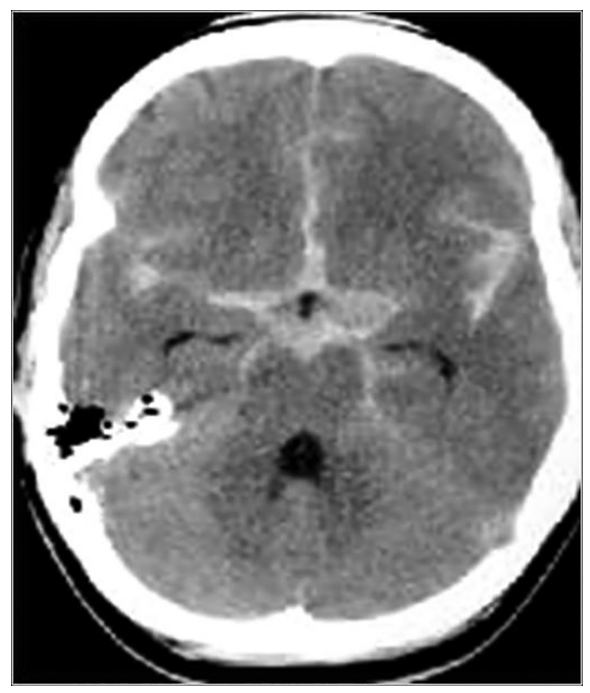

Slika 4. Kompjuterizovana tomografija kod subarahnoidalne hemoragije 


\section{Demencija nakon moždanog udara}

Demencija nakon moždanog udara (post-stroke dementia / PSD) ili kognitivno oštećenje nakon moždanog udara (post-stroke cognitive impairment / $P S C$ ) pogađa oko jedne trećine preživjelih. Opisane su različite definicije i sinonimi za PSD i PSCI. S obzirom na to da je PSD najsveobuhvatnija, predloženo je da se ovaj termin koristi za sva kognitivna oštećenja koja se razvijaju nakon moždanog udara, neposredno ili nešto kasnije (9-12).

Prevalenca PSD kreće se od 20 do $80 \%$, što varira među zemljama iz kojih stižu saopštenja, ovisno o rasi i dijagnostičkim kriterijima. Rizik za razvoj PSD vezan je kako za različite demografske faktore, kao što su dob, nivo obrazovanosti, zanimanje, tako i za različite vaskularne faktore (1). Vaskularni faktori rizika kao što su hipertenzija, diabetes mellitus, hiperlipidemija, pušenje, atrijalna fibrilacija, povećavaju rizik za razvoj kako samog MU tako i PSD. Nadalje, ponavljanje moždanih udara povećava rizik za razvoj PSD, od oko 10\% nakon prvog MU do 30\% nakon ponavljajućeg (9-12). Vaskularna demencija (VaD) uključujući PSD je drugi po redu uzrok za kognitivnu deteroraciju, nakon Alchajmerove bolesti (20-30\% svih demencija). Životni rizik za razvoj ili MU ili demencije u dobi od 65 iznosi jedan od tri muškarca i jedna od dvije žene. S promjenom populacione demografije, koja vodi sve dužoj prosječnoj životnoj dobi i sve dužem preživljavanju nakon MU, može se očekivati i sve veći broj osoba s PSD. S druge strane, s obzirom na to da je učestalost PSD vezana i za incidencu MU, moglo bi se očekivati i smanjenje učestalosti PSD s poboljšanjem prevencije MU (12-13).

Tokom vremena definicija vaskularne demencije znatno se mijenjala. Prije oko 30 godina skovan je izraz multiinfarktna demencija (MID), a označivao je bolesnike koji su razvili demenciju nakon nekoliko moždanih udara. Isti se naziv koristio i za bolesnike koji su razvili demenciju nakon samo jednoga moždanog udara, a neki su autori takvu demenciju nazivali demencija nakon moždanog udara (post-stroke dementia). Kasnije je uveden naziv vaskularna demencija koji je označivao demenciju nastalu nakon vaskularnih lezija, bez obzira na patogenezu vaskularne lezije (ishemija ili hemoragija) te bez obzira na to radi li se o jednoj ili više vaskularnih lezija.

Termini PSD i vaskularna demencija (VaD) nisu sinonimi. Danas, VaD predstavlja koncept koji uključuje ne samo multiple kortikalne i/ili supkortikalne minorne infarkte već i pojedinačne "strateške infarkte", neinfarktne lezije bijele mase, krvarenja i hipoperfuziju mozga, kao moguće uzroke 
demencije. VaD se može shvatiti i kao subgrupa VCI, predstavljajući demenciju koja se razvija jasno iza vaskularnog inzulta (10).

Demencija nakon moždanog udara (PSD) uključuje bilo koju formu demencije koja se razvija nakon cerebrovaskulanog inzulta/udara. Mada se termin "post-stroke" odnosi na stanje iza MU, istraživanja su pokazala da i tranzitorni ishemijski atak (TIA) također može biti udružen s pogoršanjem kognitivnog kapaciteta osobe koja je imala TIA. Upotreba termina PSD ne sugerira specificirani neuropatološki proces. Izgleda da u slučaju PSD imamo miješanje "vaskularnog" i neurodegenerativnog procesa. S obzirom na to da se MU predominantno dešava kod starijih osoba, moguće su situacije u kojima kognitivna deterioracija različitog stepena postoji i prije MU. Poznavanje kognitivnog statusa prije MU važno je zbog adekvatne klasifikacije, jer osoba s kognitivnom deterioracijom prije MU (dijagnostikovano i nedijagnostikovano) koja pretrpi minorni MU ne bi trebala biti shvaćena kao PSD (14-15).

Vrijeme procjene kognitivnog statusa važan je dijagnostički faktor za PSD. Naime, neposredno nakon MU se skoro redovno može utvrditi izvjestan kognitivni pad, koji se popravlja u narednih nekoliko sedmica. Zbog toga se preporučuje da se dijagnoza postojanja PSD uspostavlja najranije šest mjeseci nakon MU $(10,16)$.

\section{Klinička slika}

Bolesnici s vaskularnom demencijom boluju od kognitivnog poremećaja u aktivnostima izvršnoga funkcioniranja, kao što je organiziranje, planiranje i započinjanje radnji u određenom slijedu. Bolesnici s vaskularnom demencijom imaju relativno blagi gubitak pamćenja, ali izvršna disfunkcija nastaje relativno rano, dok je gubitak izvršne kontrolne funkcije obilježen nedostatkom planiranja, dezorijentiranim mislima, ponašanjem ili emocijama. Apatija i depresija često nastaju kao posljedica prekida prefrontalnih krugova u bolesnika nakon moždanog udara i ti simptomi čine važnu sastavnicu u razvoju vaskularne demencije (9-10).

\section{Prevencija i liječenje}

U ukupnu strategiju liječenja PSD moraju se uključiti prije svega strategije koje mogu dovesti do smanjenja onih koji dožive MU. Ovo uključuje aktivan odnos prema faktorima rizika za MU. Faktori rizika za nastanak MU mogu se podijeliti na faktore na koje se ne može uticati (nepromjenljivi) i faktore na koje se može uticati (promjenljivi) (Tabela 1). 
Važnu ulogu u redukciji incidence i mortaliteta MU predstavlja identifikacija i tretman potencijalnih faktora rizika, naročito onih na koje možemo uticati. Povišene vrijednosti krvnog pritiska čvrsto su povezane sa stopom MU u mnogim epidemiološkim studijama i osobe s jasno povišenim krvnim pritiskom imaju četiri puta veći rizik od inzulta nego normotenzivne. Bolesti srca, naročito fibrilacija pretkomora, višestruko povećavaju rizik od MU. Šećerna bolest povećava osjetljivost prema koronarnoj, femoralnoj i cerebralnoj aterosklerozi, pogotovu ako je udružena s hiperlipidemijom i gojaznošću. Osobe s dokazanom šećernom bolešću imaju dva puta veći rizik za pojavu MU. Uživanje duhana jasno je utemeljeno kao biološki pouzdana i nezavisna determinanta u povećanju incidence MU. Pušenje povećava rizik od inzulta za 2,5 puta kod muškaraca i 3,1 put kod žena (7). Zahvaljujući promjeni načina života i smanjenju faktora rizika te boljem zbrinjavanju bolesnika $\mathrm{s}$ MU, incidenca ove bolesti u razvijenim zemljama se smanjila, a mortalitet je reduciran.

Tabela 1. Faktori rizika za nastanak moždanog udara

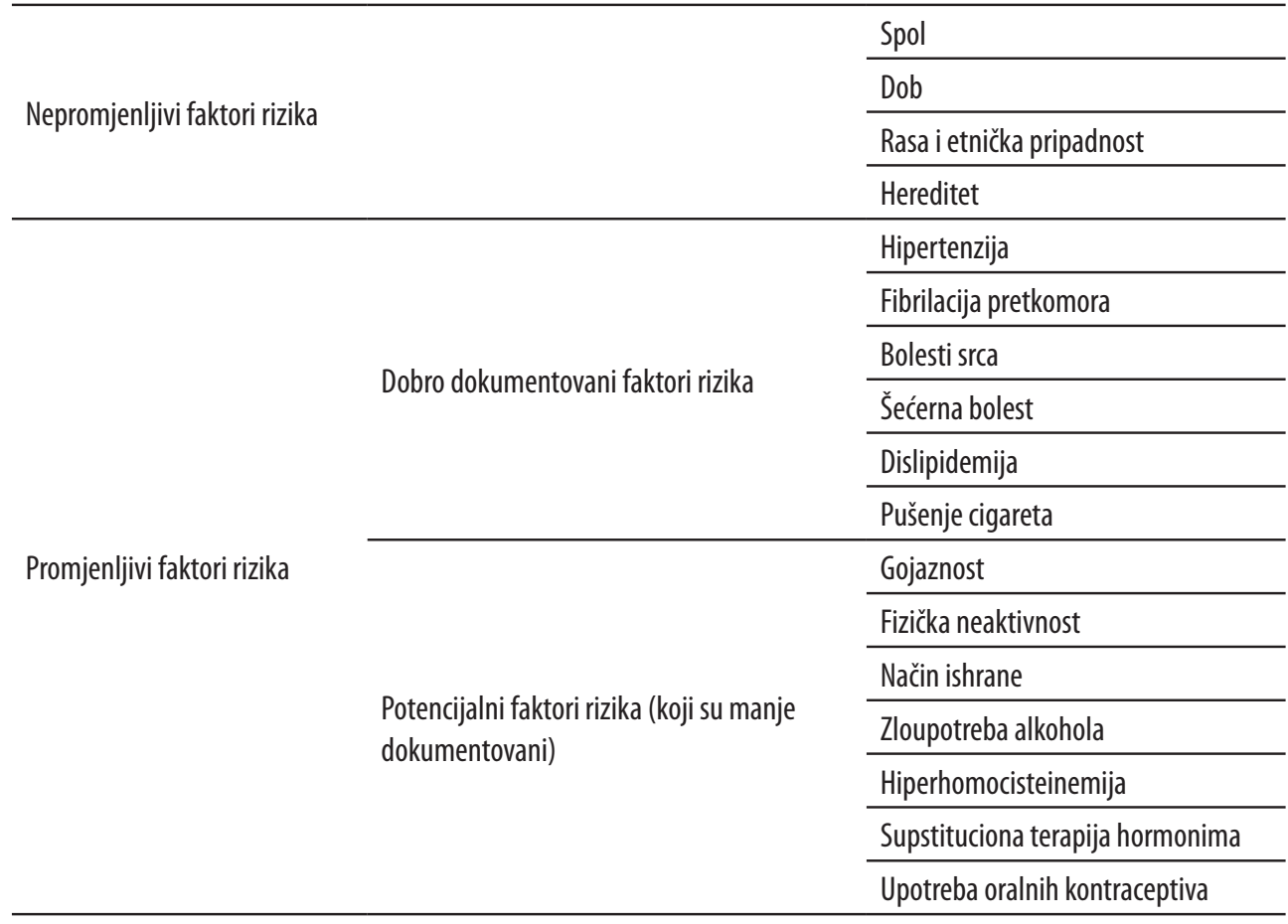

Dakle, prevencija PSD može se postići prije svega prevencijom MU, ali i uticajem na neke od faktora rizika za PSD (Tabela 2). Na drugoj strani primjenjuju se različite strategije u cilju ublažavanja kliničkog toka PSD, kao 
što je smanjenje krvnog pritiska, primjena statina, neuroprotektivnih i antiinflamatornih lijekova, bez uvjerljivih dokaza njihove efikasnosti. Analiziraju se i mogući pozitivni učinci intervencija u sferi životnih stilova, učinci različitih fizičkih aktivnosti, kognitivnog treninga i dr. (1, 10, 17-18).

Tabela 2. Faktori rizika za razvoj demencije nakon moždanog udara

\begin{tabular}{|c|c|}
\hline \multirow{3}{*}{ Demografski faktori } & Dob (preko 65 godina) \\
\hline & Nizak nivo obrazovanja \\
\hline & Ženski spol \\
\hline \multirow{2}{*}{ Faktori prije MU } & Fizička neaktivnost \\
\hline & Kognitivno propadanje \\
\hline \multirow{4}{*}{ Faktori vezani za MU } & Hemoragijski MU \\
\hline & Supratentorijalna lokacija MU \\
\hline & MU u dominantnoj hemisferi \\
\hline & Rekurentni MU \\
\hline \multirow{3}{*}{ Faktori nakon MU } & Infekcija \\
\hline & Delirij \\
\hline & Razne krize svijesti \\
\hline \multirow{3}{*}{ "Neuroimaging" faktori } & Bolest malih moždanih krvnih žila \\
\hline & Kortikalna atrofija \\
\hline & Atrofija medijalnog temporalnog lobusa \\
\hline
\end{tabular}

Za sada ne postoji uvjerljiv efikasni tretman PSD, ali lijekovi koji se primjenjuju u tretmanu Alchajmerove demencije (holinesterazni inhibitori, memantin) ipak pokazuju određenu efikasnost. Nadalje, u toku su različite kliničke studije koje su obećavajuće.

\section{Reference}

1. Sun JH, Tan L, Yu JT. Post-stroke cognitive impairment: epidemiology, mechanisms and management. Ann Transl Med. 2014;8:80. doi: 10.3978/j.issn.2305-5839.2014.08.05.

2. Bender M, Jusufović E, Railić V, Kelava S, Tinjak S, Dževdetbegović D, Mot D, Trešnjo M, Lakičević S, Pejanović-Skobić N, Sinanović O. High burden of stroke risk factors in developing country: the case study of Bosnia-Herzegovina. Mater Sociomed. 2017;29(4):277-9. doi: 10.5455/msm.2017.29.277-279.

3. Booth J, Connelly L, Lawrence M, Chalmers C, Joice S, Becker C, Dougall N. Evidence of perceived psychosocial stress as a risk factor for stroke in adults: a meta-analysis. BMC Neurol. 2015;15:233. doi: 10.1186/s12883-015-0456-4.

4. Yang Q, Tong X, Schieb L, Vaughan A, Gillespie C, Wiltz JL, King SC, Odom E, Merritt R, Hong Y, George MG. Vital Signs: Recent Trends in Stroke Death Rates - United States, 
2000-2015. MMWR Morb Mortal Wkly Rep. 2017;66(35):933-9. doi: 10.15585/mmwr. $\mathrm{mm} 6635 \mathrm{e} 1$.

5. Benjamin E, Virani SS, Callaway CW, Chamberlain AM, Chang AR, Cheng S, Chiuve SE, Cushman M, Delling FN, Deo R, de Ferranti SD, Ferguson JF, Fornage M, Gillespie C, Isasi CR, Jiménez MC, Jordan LC, Judd SE, Lackland D, Lichtman JH, Lisabeth L, Liu S, Longenecker CT, Lutsey PL, Mackey JS, Matchar DB, Matsushita K, Mussolino ME, Nasir K, O'Flaherty M, Palaniappan LP, Pandey A, Pandey DK, Reeves MJ, Ritchey MD, Rodriguez CJ, Roth GA, Rosamond WD, Sampson UKA, Satou GM, Shah SH, Spartano NL, Tirschwell DL, Tsao CW, Voeks JH, Willey JZ, Wilkins JT, Wu JH, Alger HM, Wong SS, Muntner P. American Heart Association Council on Epidemiology and Prevention Statistics Committee and Stroke Statistics Subcommittee. Heart Disease and Stroke Statistics - 2018 Update: A Report From the American Heart Association. Circulation. 2018;137(12):e67-e492. doi: 10.1161/CIR.0000000000000558.

6. Kadojić D, Demarin V, Dikanović M, Lusić I, Tuskan-Mohar L, Trkanjec Z, Mihaljević I, Kadojić M, Bitunjac M, Vranjes Z. Incidence of Stroke and Transient Ischemic Attack in Croatia: A Population Based Study. Coll Antropol. 2015;39(3):723-7.

7. Sinanović O i saradnici. Neurologija. Tuzla: Infograf Tuzla i Uduženje neurologa TK, 2012.

8. Demarin V, Sinanović O, Trkanjec Z. Neurovaskularne bolesti i moždani udar. U: Sinanović O, Trkanjec Z i suradnici. Nemotorni simptomi nakon moždanog udara. Zagreb: Medicinska naklada, 2015. str. 1-26.

9. Trkanjec Z. Vaskularni kognitivni poremećaji. U: Sinanović O, Trkanjec Z i suradnici. Nemotorni simptomi nakon moždanog udara. Zagreb: Medicinska naklada, 2015. str. 27-44.

10. Mijajlović MD, Pavlović A, Brainin M, Heiss WD, Quinn TJ, Ihle-Hansen HB, Hermann DM, Assayag EB, Richard E, Thiel A, Kliper E, Shin YI, Kim YH, Choi S, Jung S, Lee YB, Sinanović O, Levine DA, Schlesinger I, Mead G, Milošević V, Leys D, Hagberg G, Ursin MH, Teuschl Y, Prokopenko S, Mozheyko E, Bezdenezhnykh A, Matz K, Aleksić V, Muresanu D, Korczyn AD, Bornstein NM. Post-stroke dementia - a comprenhensive review. BMC Med. 2017;15(1):11. doi: 10.1186/s12916-017-0779-7.

11. Sahathevan R, Brodtmann A, Donnan GA. Dementia, stroke, and vascular risk factors: a review. Int J Stroke. 2012;7:61-73.

12. Pendlebury ST, Rothwell PM. Prevalence, incidence, and factors associated with prestroke and post-stroke dementia: a systematic review and meta-analysis. Lancet Neurol. 2009;8:1006-18.

13. Sehsadri S, Wolf PA. Lifetime risk of stroke and dementia: current concepts, and estimates from the Framingham Study. Lancet Neurol. 2007;3:1106-14.

14. Henon H, Pasquier F, Durieu I, Godefroy O, Lucas C, Lebert F, Leys D. Preexisting dementia in stroke patients. Baseline frequency, associated factors, and outcome. Stroke. 1997;28:2429-36.

15. Brainin M, Tuomilehto J, Heiss WD, Bornstein NM, Bath PM, Teuschl Y, Richard E, Guekht A, Quinn T. Post Stroke Cognition Study Group. Post-stroke cognitive decline: an update and perspectives for clinical research. J Neurol. 2015;22:229-38. doi: 10.1111/ ene. 12626.

16. Wagle J, Farner L, Flekkøy K, Bruun Wyller T, Sandvik L, Fure B, Stensrød B, Engedal K. Early post-stroke cognition in stroke rehabilitation patients predicts functional outcome at 13 months. Dement Geriatr Cogn Disord. 2011;31:379-87. doi: 10.1159/000328970. 
17. Sharp SI, Aarsland D, Day S, et al. Hypertension is a potential risk factor for vascular dementia: systematic review. Int J Geriatr Psychiatry. 2011;26:661-9.

18. Pendlbury ST, Rothwell PM. Prevalence, incidence, and factors associated with prestroke and post-stroke dementia: a systematic review and meta-analysis. Lancet Neurol. 2009;8:1006-8. doi: 10.1016/S1474-4422(09)70236-4. 


\title{
POSTSTROKE DEMENTIA
}

\begin{abstract}
Stroke or cerebrovascular insult (CVI) - which can be defined as a brain dysfunction caused by a disruption of blood flow through the brain - is the second most common cause of adult death in the world population (1). CVI affects 33 million people each year worldwide and one-third of CVI occurs in developing countries. Post-stroke dementia (PSD) or post-stroke cognitive impairment (PSCI) affects about one-third of survivors. Different definitions and synonyms for PSD and PSCI are described. Since PSD is the most comprehensive, it is suggested that this term be used for all cognitive impairments which develop after a stroke, immediately or somewhat later. The prevalence of PSD ranges from 20 to $80 \%$, which varies among the countries from which the reports come, depending on the race and diagnostic criteria. The risk for developing PSD is related to various demographic factors such as age, level of education, occupation, and various vascular factors (1,3-4). Vascular risk factors such as hypertension, diabetes mellitus, hyperlipidemia, smoking, atrial fibrillation, increase the risk of developing both CVI and PSD. Furthermore, recurrence of strokes increases the risk of developing PSD, from about $10 \%$ after the first stroke to $30 \%$ after the recurrent stroke. Prevention of PSD can be achieved primarily by prevention of CVI. On the other hand, various strategies are applied to alleviate the clinical course of PSD, such as lowering blood pressure, application of statins, neuroprotective and anti-inflammatory drugs, without convincing evidence of their effectiveness. Possible positive effects of interventions in the sphere of lifestyles, the effects of various physical activities, cognitive training, etc. are also analysed. For now, there is no convincingly effective treatment for PSD, but drugs used in the treatment of Alzheimer's dementia (cholinesterase inhibitors, memantine) still show some effectiveness. Furthermore, various promising clinical studies are underway $(1,3)$.
\end{abstract}

Keywords: poststroke dementia, prevalence, risk factors, prevention, treatment. 